\title{
A Terahertz Imaging System with Rotation Mirror
}

\author{
Chengwu You, Jinsong Liu, Kejia Wang, Zhengang Yang* \\ Wuhan National Laboratory for Optoelectronics, Huazhong University of Science and Technology, Wuhan, China \\ Email: ^mikleyang@163.com
}

How to cite this paper: You, C.W., Liu, J.S., Wang, K.J. and Yang, Z.G. (2020) A Terahertz Imaging System with Rotation Mirror. Journal of Computer and Communications, 8, 295-302. https://doi.org/10.4236/jcc.2020.812024

Received: September 22, 2020 Accepted: December 24, 2020 Published: December 31, 2020

\begin{abstract}
In this article, a THz imaging system with rotation mirror is built. The system considers both imaging speed and cost of hardware. The transmission-mode design realizes miniaturization of the system. With the system, we are able to acquire image size of $60 \times 80 \mathrm{~mm}^{2}$ in 60 seconds, while a raster-scan $\mathrm{THz}$ imaging system with the same hardware conditions needs more than $30 \mathrm{mi}-$ nutes. Moreover, internal information of object could be got with the $\mathrm{THz}$ imaging system reported in this article.
\end{abstract}

\section{Keywords}

Terahertz, Imaging, Nondestructive Testing, Rotation Mirror

\section{Introduction}

Terahertz $(\mathrm{THz})$ radiation is a kind of electromagnetic radiation located in a specific wave band. The specific wave band, locating between the microwave and infrared frequencies, is from $10^{11} \mathrm{~Hz}$ to $10^{13} \mathrm{~Hz}$ [1]. Terahertz radiation has an ability to penetrate many materials, such as foam [2], ceramic [3], magnetic material [4] and polymer composites [5] and so on. Therefore, $\mathrm{THz}$ technology has been widely used in non-destructive testing as an established powerful tool [6] [7] [8]. THz applications in such fields as pharmaceutical solid dosage forms [9], dental tissues [10], coating layers [11] [12] [13] [14], glass fiber [15], painting on canvas [16], corrosion under metallic source material [17] et al. have proved to be significant scientific and practical. With the development of $\mathrm{THz}$ technology, research for THz spectroscopy and imaging is held on a large scale [18] [19]. However, imaging speed and cost of hardware are contradictory in $\mathrm{THz}$ imaging. While the terahertz camera is expensive, the imaging speed of raster-scan $\mathrm{THz}$ imaging system is slow. In this paper, a THz imaging system with rotation 
mirror is built. The system is an effective THz imaging system, considering both speed and cost. The transmission-mode design miniaturizes the system. With the system, we are able to acquire image size of $60 \times 80 \mathrm{~mm}^{2}$ in 60 seconds, while a raster-scan $\mathrm{THz}$ imaging system with the same hardware conditions needs more than 30 minutes. Moreover, internal information of object could be got with the THz imaging system.

\section{General Setup}

\subsection{Diagram of the System}

Diagram of the THz imaging system with rotation mirror is shown in Figure 1. When a sample is scanned, the probe wave transmitted by the $0.3 \mathrm{THz}$ source passes through the shaping lens and then casts on the rotation mirror. As the rotation mirror rotates reflected wave scans the sample. Reflected waves through the sample are converged at the detector by collecting lens.

\subsection{Source of the System}

The source of the system is a THz Impact Ionization Avalanche Transit-Time (IMPATT) diode produced by TeraSense Company. A physical map of the source is shown in Figure 2. Table 1 shows the specifications of the IMPATT diode.

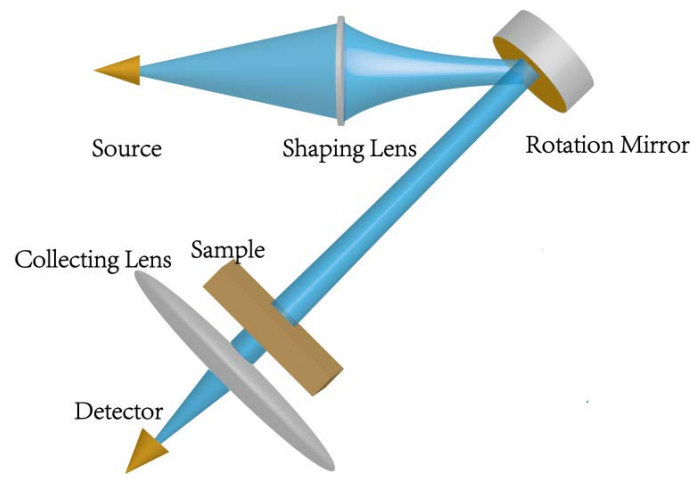

Figure 1. Diagram of the $\mathrm{THz}$ imaging system with rotation mirror.



Figure 2. Physical map of the $\mathrm{THz}$ source. 
Table 1. Specifications of the IMPATT diode.

\begin{tabular}{cc}
\hline Performance parameters of the IMPATT diode & Value \\
\hline frequency & $0.3 \mathrm{THz}$ \\
input power & $80 \mathrm{~mW}$ \\
Output power & $2 \mathrm{~mW}$ \\
Working current & $110-120 \mathrm{~mA}$ \\
Typical linewidth & $1 \mathrm{MHz}$ \\
TTL modulation & $1 \mu \mathrm{s}$ rise/fall time \\
\hline
\end{tabular}

\subsection{Detector of the System}

The detector of the system is a high electron mobility field-effect transistor (FET) based on GaN/AlGaN bow-tie antenna enhancement technique. Physical map of the source can be found in Figure 3 and more specifications of the FET can be found in Table 2 .

\subsection{Electric Control Rotation Mirror of the System}

The electric control rotation mirror of the System, including a fast rotation bearing, a slow rotation bearing and a reflector, is produced by OP Mount Instrument Inc. Physical map of the rotation mirror can be found in Figure 4 and more specifications of the FET can be found in Table 3.

\section{Data Acquisition and Image Reconstruction}

\subsection{Data Acquisition}

When the $\mathrm{THz}$ imaging system is working, the quick bearing is rotating at $60^{\circ} / \mathrm{s}$ and the slow bearing is rotating at $0.2 \%$. The system recorded the signal when the fast bearing angular displacement is round number in angular unit. Diagram of sampling is shown in Figure 5.

\subsection{Image Reconstruction}

Firstly, data collected from the system are mapped to corresponding points in Cartesian coordinates. Then, the points are connected with triangles as shown in Figure 6, using the Delaunay algorithm [20]. Padding triangles mentioned above, final image can be obtained.

\section{Experiment and Results}

\subsection{Experiment Setup}

Photography of the experimental set up is shown in Figure 7. The sample is composed of three layers. As shown in Figure 8, there is a metal layer sandwiched between 2 pieces of cardboard.

\subsection{Experiment}

3 samples with metal layer in different shapes are tested in the experiment. The 3 


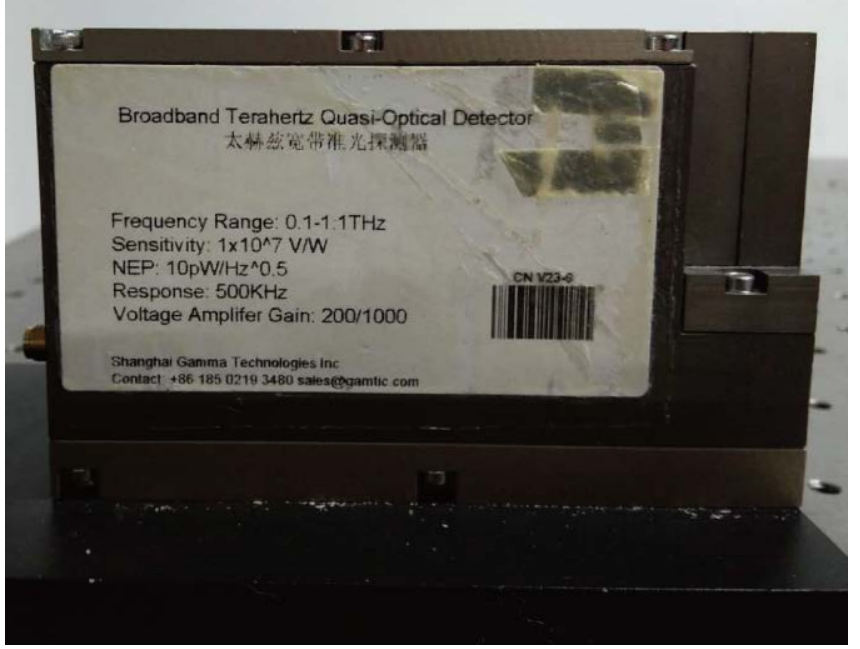

Figure 3. Physical map of the $\mathrm{THz}$ detector.

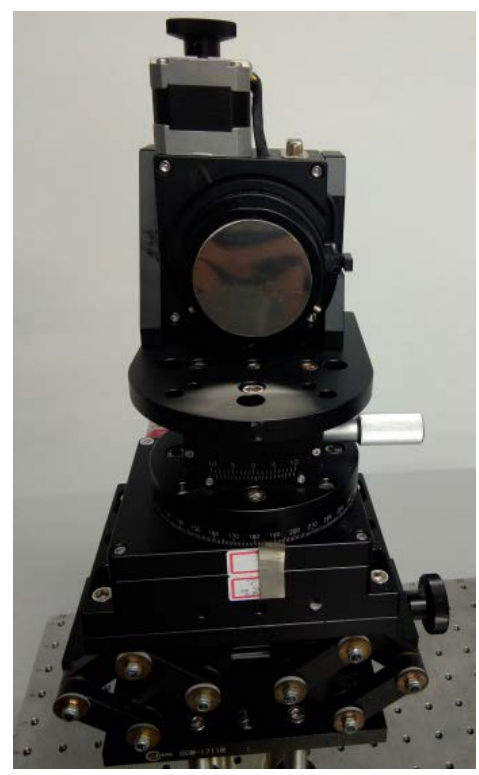

Figure 4. Physical map of the electric control rotation mirror.

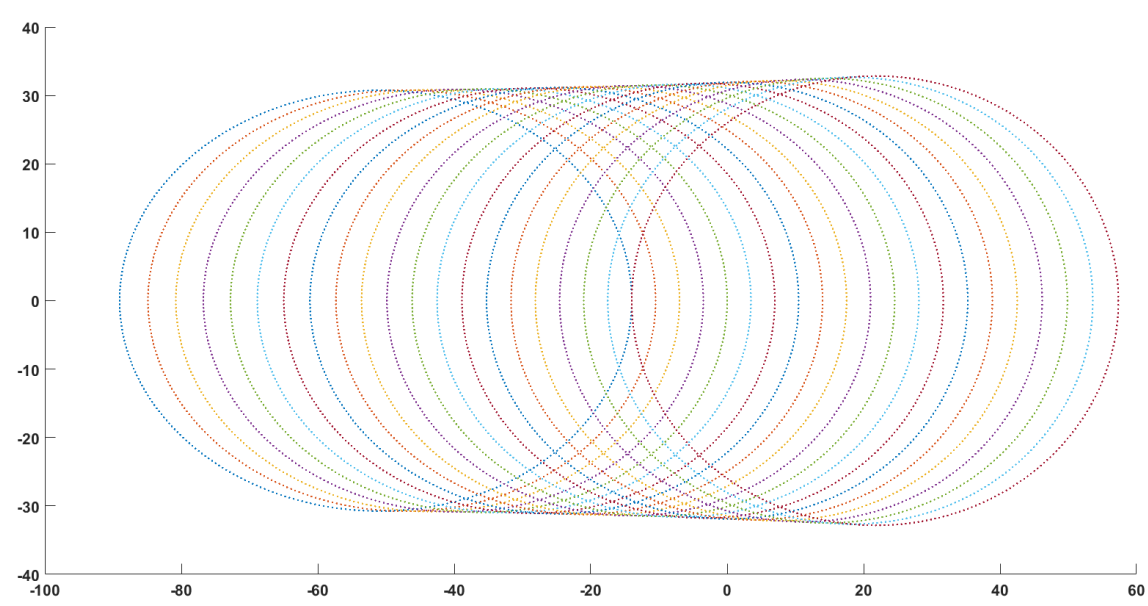

Figure 5. Diagram of sampling. 


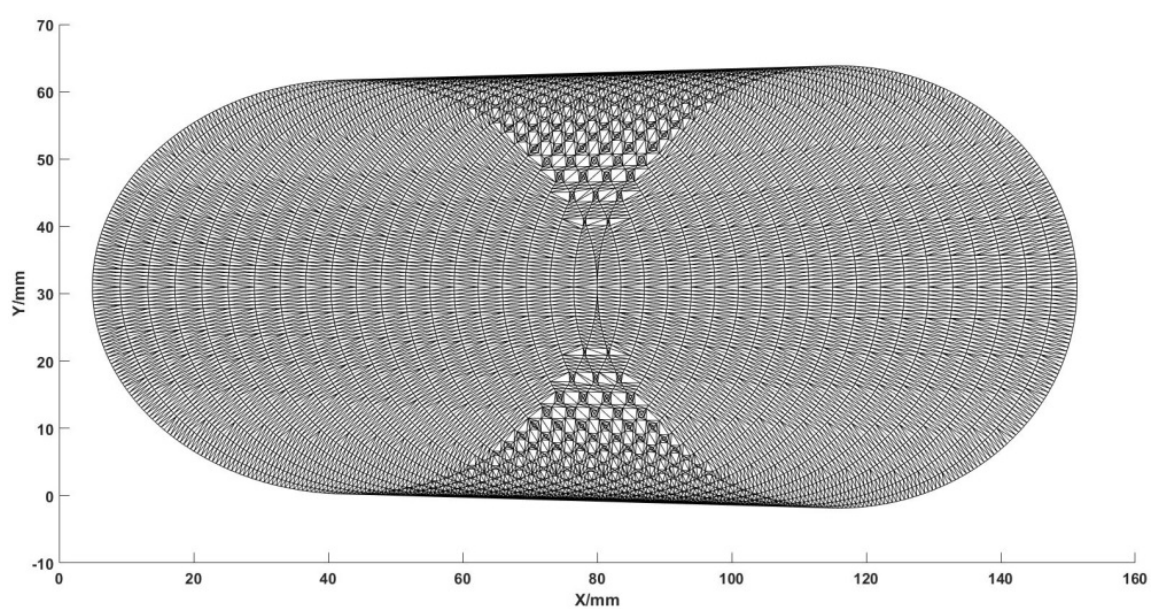

Figure 6. schematic of tiangulation.

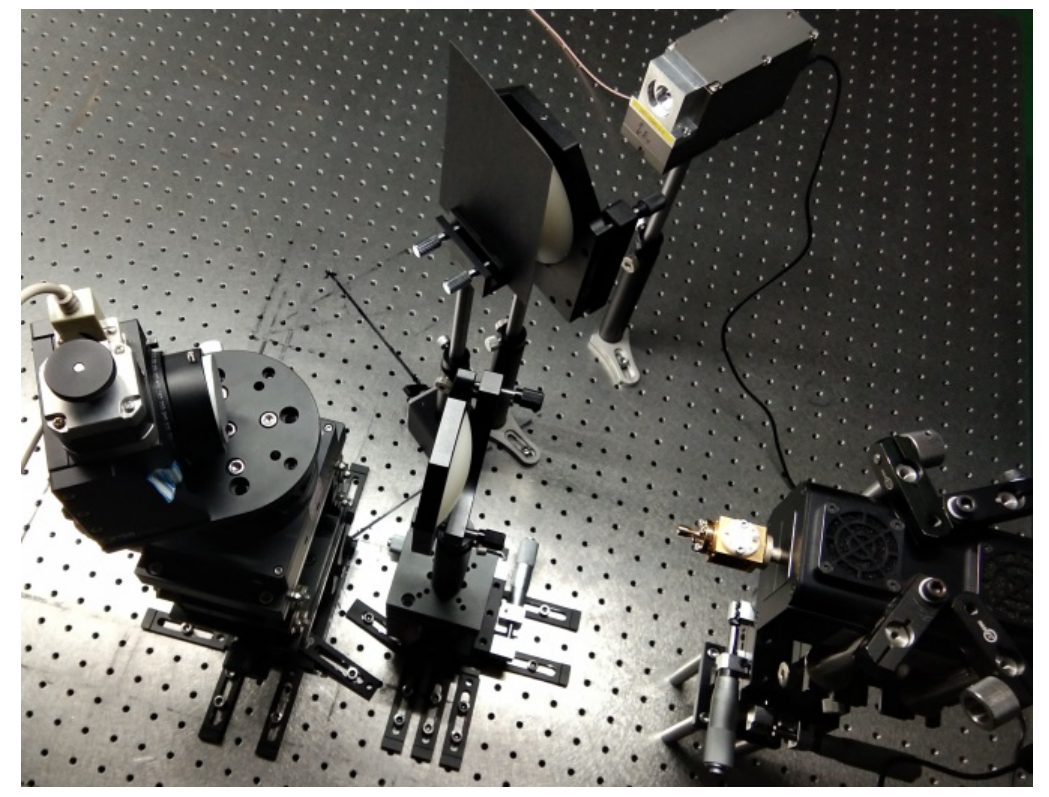

Figure 7. Photography of the experimental set up.

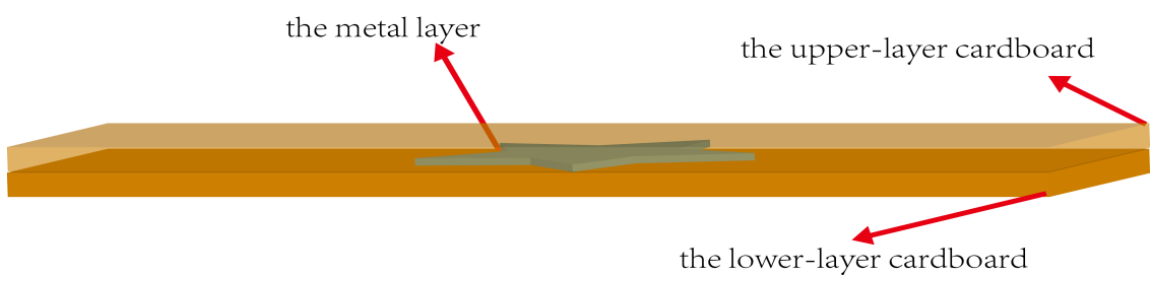

Figure 8. Schematic of sample.

samples were named "sample A", "sample B" and "sample C" respectively. The shape of sample A's metal layer can be found in Figure 9(a); the shape of sample B's metal layer can be found in Figure 9(b); the shape of sample C's metal layer can be found in Figure 9(c). Experiment results of the 3 samples are shown in Figures 9(d)-(f). According to Figure 9, it can be clearly seen that the shape of the metal layer can be recognized effectively. 
Table 2. Specifications of the FET.

\begin{tabular}{cc}
\hline Performance parameters of the FET & Value \\
\hline Frequency response range & $0.1-1.15 \mathrm{THz}$ \\
Responsivity & $1 \times 10^{7} \mathrm{~V} / \mathrm{W}$ \\
NEP & $10 \mathrm{pW} / \mathrm{Hz}^{0.5}$ \\
Response Speed & $500 \mathrm{kHz}$ \\
Input mode & $\mathrm{AC} / \mathrm{DC}$ \\
Gain of voltage amplifier & $200 / 100$ \\
\hline
\end{tabular}

Table 3. Specifications of the electric control rotation mirror.

\begin{tabular}{cc}
\hline Performance parameters of the FET & Value \\
\hline Speed of fast rotation bearing & $0^{\circ}-100^{\circ} / \mathrm{s}$ \\
Speed of low rotation bearing & $0^{\circ}-50^{\circ} / \mathrm{s}$ \\
Icline angle of reflector & $5^{\circ}$ \\
\hline
\end{tabular}
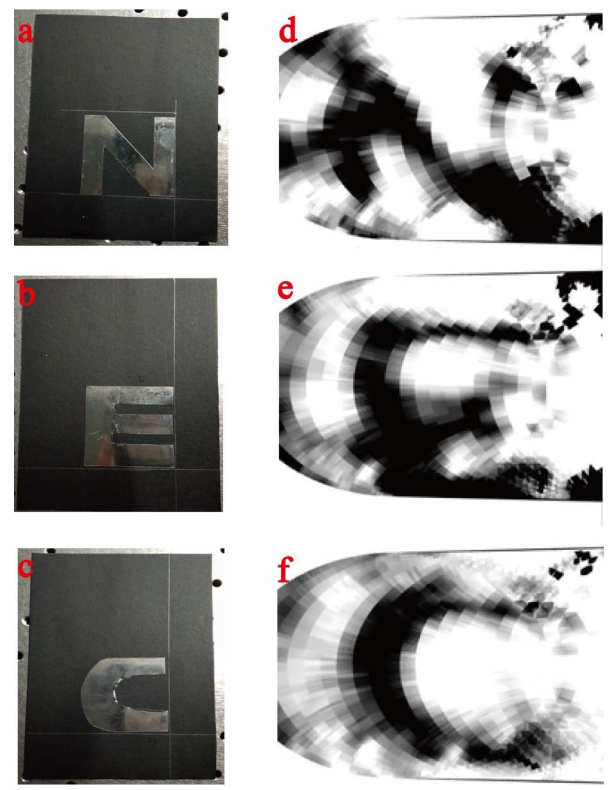

Figure 9. Photography of the metal layer in the 3 samples and experimental results. (a) sample A's metal layer; (b) sample B's metal layer; (c) sample C's metal layer; (d) experimental results of sample A; (e) experimental results of sample B; (f) experimental results of sample C.

\section{Conclusion}

A THz imaging system with rotation mirror is built in this article. The system based on a two-dimensional rotating scanner has the ability to acquire an image sized at $60 \times 80 \mathrm{~mm}^{2}$ in 60 seconds while a raster-scan THz imaging system with the same hardware conditions needs more than 30 minutes. According to the experiment in chapter 4 , it can be found that the system has the ability to detect the information of inner layer of objects effectively. 


\section{Conflicts of Interest}

The authors declare no conflicts of interest regarding the publication of this paper.

\section{References}

[1] Zhang, X.C. and Xu, J. (2010) Introduction to THz Wave Photonics, Springer US. https://doi.org/10.1007/978-1-4419-0978-7

[2] Abina, A., Puc, U., Jeglič, A. and Zidanšek, A. (2013) Structural Analysis of Insulating Polymer Foams with Terahertz Spectroscopy and Imaging. Polymer Testing, 32, 739-747. https://doi.org/10.1016/j.polymertesting.2013.03.004

[3] Kirihara, S., Niki, T. and Kaneko, M. (2009) Terahertz Wave Behaviours in Ceramic and Metal Structures Fabricated by Spatial Joining of Micro-Stereolithography. Article ID: 012082. https://doi.org/10.1088/1742-6596/165/1/012082

[4] He, Y.-H. and Li, J.-S. (2011) Terahertz Spectroscopic Investigation of Magnetic Materials. Article ID: 012206. https://doi.org/10.1088/1742-6596/276/1/012206

[5] Yakovlev, E.V., Zaytsev, K.I., Dolganova, I.N. and Yurchenko, S.O. (2015) Non-Destructive Evaluation of Polymer Composite Materials at the Manufacturing Stage Using Terahertz Pulsed Spectroscopy. IEEE Transactions on Terahertz Science \& Technology, 5, 810-816. https://doi.org/10.1109/TTHZ.2015.2460671

[6] Jansen, C., Wietzke, S., Peters, O., Scheller, M., Vieweg, N., Salhi, M., Krumbholz, N., Jördens, C., Hochrein, T. and Koch, M. (2010) Terahertz Imaging: Applications and Perspectives. Appl Opt, 49, 48-57. https://doi.org/10.1364/AO.49.000E48

[7] Ahi, K. and Anwar, M. (2016) Advanced Terahertz Techniques for Quality Control and Counterfeit Detection. In: SPIE Commercial + Scientific Sensing and Imaging. Article ID: 98560G. https://doi.org/10.1117/12.2228684

[8] Zhang, H., Sfarra, S., Sarasini, F., Ibarra-Castanedo, C., Perilli, S., Fernandes, H., Duan, Y., Peeters, J., Avelidis, N.P. and Maldague, X. (2017) Optical and Mechanical Excitation Thermography for Impact Response in Basalt-Carbon Hybrid Fiber-Reinforced Composite Laminates. IEEE Transactions on Industrial Informatics, p. 1. https://doi.org/10.1109/TII.2017.2744179

[9] Zhong, S., Shen, Y.C., Ho, L., May, R.K., Zeitler, J.A., Evans, M., Taday, P.F., Pepper, M., Rades, T. and Gordon, K.C. (2011) Non-Destructive Quantification of Pharmaceutical Tablet Coatings Using Terahertz Pulsed Imaging and Optical Coherence Tomography. Optics \& Lasers in Engineering, 49, 361-365. https://doi.org/10.1016/j.optlaseng.2010.11.003

[10] Crawley, D., Longbottom, C., Wallace, V.P., Cole, B., Arnone, D. and Pepper, M. (2003) Three-Dimensional Terahertz Pulse Imaging of Dental Tissue. Journal of Biomedical Optics, 8, 303. https://doi.org/10.1117/1.1559059

[11] Geltner, I., Hashimshony, D. and Zigler, A. (2002) Detection and Electrical Characterization of Hidden Layers Using Time-Domain Analysis of Terahertz Reflections. Journal of Applied Physics, 92, 203-206. https://doi.org/10.1063/1.1486035

[12] White, J. and Zimdars, D. (2007) Time Domain Terahertz Non Destructive Evaluation of Water Intrusion in Composites and Corrosion under Insulation. Quantum Electronics and Laser Science Conference, 1-2. https://doi.org/10.1109/QELS.2007.4431367

[13] Lopato, P. and Chady, T. (2013) Terahertz Detection and Identification of Defects in Layered Polymer Composites and Composite Coatings. Nondestructive Testing 
\& Evaluation, 28, 28-43. https://doi.org/10.1080/10589759.2012.694882

[14] Anastasi, R.F. and Madaras, E.I. (2006) Terahertz NDE for Under Paint Corrosion Detection and Evaluation. 515-522. https://doi.org/10.1063/1.2184571

[15] Jördens, C., Scheller, M., Wietzke, S., Romeike, D., Jansen, C., Zentgraf, T., Wiesauer, K., Reisecker, V. and Koch, M. (2010) Terahertz Spectroscopy to Study the Orientation of Glass Fibres in Reinforced Plastics. Composites Science \& Technology, 70, 472-477. https://doi.org/10.1016/j.compscitech.2009.11.022

[16] Zhang, H., Sfarra, S., Saluja, K., Peeters, J., Fleuret, J., Duan, Y., Fernandes, H., Avdelidis, N., Ibarra-Castanedo, C. and Maldague, X. (2017) Non-Destructive Investigation of Paintings on Canvas by Continuous Wave Terahertz Imaging and Flash Thermography. Journal of Nondestructive Evaluation, 36, 34.

https://doi.org/10.1007/s10921-017-0414-8

[17] Jackson, J.B., Labaune, J., Mourou, G.A. and D’Alessandro, L. (2011) Pulsed Terahertz Investigation of Corroded and Mineralized Copper Alloy Historical Artifacts. International Conference on Infrared, Millimeter and Terahertz Waves, 1-2. https://doi.org/10.1109/irmmw-THz.2011.6104844

[18] Fattinger, C., Grischkowsky, D., Exter, M.V. and Keiding, S. (1990) Far-Infrared Time-Domain Spectroscopy with Terahertz Beams of Dielectrics and Semiconductors. Journal of the Optical Society of America B, 7, 2006-2015. https://doi.org/10.1364/JOSAB.7.002006

[19] Stoik, C., Bohn, M. and Blackshire, J. (2010) Nondestructive Evaluation of Aircraft Composites Using Reflective Terahertz Time Domain Spectroscopy. Ndt \& E International, 43, 106-115. https://doi.org/10.1016/j.ndteint.2009.09.005

[20] Barber, C.B., Dobkin, D.P. and Huhdanpaa, H. (1998) The Quick Hull Algorithm for Convex Hulls. ACM Transactions on Mathematical Software, 22. https://doi.org/10.1145/235815.235821 